\title{
STUDENTS' PERCEPTIONS OF AND ATTITUDES THE USE OF ONLINE LEARNING PLATFORM FOR LEARNING IN THE PANDEMIC TIME
}

\author{
Kurniatul Aini $^{1^{*}}$, Untung Waluyo ${ }^{2}$, Henny Soepriyanti ${ }^{3}$ \\ University of Mataram \\ *e-mail: kurniatulaini873@gmail.com
}

\begin{abstract}
The use of online learning platform becomes compulsory use after Covid- 19 came in 2019 in Indonesia. Learning by using online learning platforms during the pandemic becomes the newest thing for students. Thus, this research study aimed to (a) investigate students' perceptions of the use of online learning platforms for learning during the pandemic and (b) reveal students' attitudes toward learning by using online learning platform during the pandemic. The data were collected by interviewing 8 students of English department in one of state universities in West Nusa Tenggara. Besides, observation and document studies were conducted to support findings from the interview data. The research employed a qualitative research method. In general, the present study has yielded disadvantages and the advantages of employing online learning platform during the pandemic time. The study also reveals students' learning attitudes toward use of online learning platforms during the pandemic. The results of the study confirm that, students' success or failure was largely caused by internal or external factors.

Keywords: Online Learning Platform, Perception, Attitude
\end{abstract}

\section{INTRODUCTION}

Nowadays, most higher education students are increasingly updated to the newer technology for learning purposes. The presence of new technology is often perceived positively by most students and teachers (Al-Bataineh, Banikalef, \& Albashtawi, 2019). In many instances, the utilization of such a technology is appealing for teachers and students to explore new ways of learning. Thus, eventually this drives researchers and web designers to develop different technological pedagogical innovation in the form of online learning platforms. This enables teachers or lecturers to interact with students beyond the traditional practice of face-to-face meeting.

The spread of the Corona virus has strengthened the position of online tool as a long-distance learning medium. The pandemic phenomenon has caused the compulsory use of the online learning platform for learning. Despite such a progress, conducting online classes using different learning platforms during the pandemic may bring about negative responses from most students. Students might feel burdensome or threatened due to their unfamiliarity with the new learning platform. Similarly, the lecturers may find it more difficult to provide meaningful feedback when they are short of technology services (Marshall, Shannon, Love, 2020).

A number of research studies conducted by various researchers during the pandemic time have yielded some explanation about the advantages and disadvantages of using online platforms. Babayigit, Cizreliogullari, Altun (2020), for example, has reported that the students developed both positive and negative attitudes toward online learning. Some students might feel secure and relaxed in using the platform in the online learning process, while others might feel insecure and threatened. The shift of instruction and modes of learning from conventional media to computer-based media has eventually brought about challenges to both teachers and students (Clark \& Mayer, 2016).

As regards the mode of instruction, Almpanis et al. (2011) describe two generic terms for online engagement, i.e. Synchronous and Asynchronous Learning. The term synchronous learning is referred to a digital version of classroom meeting or virtual classroom. Synchronous learning 
can be used to design interactions for learning (Bower, 2016; Garrison et al., 2000). Synchronous closely similar regular learning and communication occur in realtime using technology. In synchronous, the teacher leads the discussion, the teacher may pose the materials and the students can access using features in web- based conferencing system. Synchronous learning is usually implemented through the use of video conferencing tools, Microsoft Moodle, web-based seminar and chat room. Synchronous online learning platform is also studied by a number of researchers. Jan (2020), for example, investigated a phenomenological study of synchronous teaching during Covid-19, a case of an international school in Malaysia. This study explored some issues which were faced by students and their parents during synchronous online learning. Results of the study showed that the problem in conducting online learning is identified in students; lack of developing the social skills.

Conversely the term asynchronous online learning is referred to students' higher flexibility in accessing materials and interacting with other students through internet platform. This enables them to learn the content of learning materials at their own pace. (Hrastinski, 2008; Lucas, Gunawardena, \& Moreira, 2014) mention the flexibility of asynchronous as the advantage that allows students to reflect on their learning content at their own time. Asynchronous makes it possible for teachers to leave the learning materials such as video recording, documents, messages, and voice note for the students so that they may discuss and/or interact with their teachers at any convenient time. Asynchronous learning is commonly facilitated through the use of media such as e-mail, Moodle, Google Classroom.

Another term that is worth mentioning here is the hybrid learning mode. The term hybrid learning is referred to a mixture of both synchronous and asynchronous learning modes. It is the combination of online and face to face instruction (Brunner, 2007). Thus far, the utilization of hybrid learning mode has become a trend in online education. Garnham \& Kaleta (2002) \& Young (2002) mention that hybrid learning offers many advantages, which include flexibility, convenience, interactions, and increased learning and retention. Other researchers, such as Albashtawi, Albataineh (2020), Chourishi, Buttan, Chaurassia, Soni (2011) mention that asynchronous online learning has brought advantages in language learning, especially in the enhancement of reading and writing performance.

Further, the combined use of synchronous and asynchronous learning modes is referred to hybrid online learning. The study conducted by Patricia (2020) has showed that students who used to study using asynchronous mode were inclined to be significantly more motivated to take part positively in the blended learning. These students were more frequently welladjusted to the use of learning technology after they were facilitated to use the asynchronous online learning platform. Despite such virtues, this study also revealed that students' self-efficacy decreased some communication skills such as the ability to discuss the topic with classmates, the ability to complete task on time, ability to succeed in classes, and the ability to manage time.

The researcher employed three theories to account for the phenomenon investigated in this study. The first theory is Behaviorism. The proponent of this learning theory was Skinner. The second theory is Vygotsky's social constructivism. The third theory is Piaget's cognitivism. As regards the social constructivism, the researcher borrows the theory of online collaborative learning proposed by Harasim (2012) to look at how online learning is collaboratively constructed by the learners. To reveal students' learning attitudes toward using online learning platforms during the pandemic, the Attribution Theory developed by Heider (1958) and 
Weiner (1972) is revisited. This theory is used to frame the cause of success and failures of students' learning based on the components of Attribution Theory i.e., (1) Locus of control; (2) Stability; (3) Controllability.

\section{RESEARCH METHODS}

The researcher employed a qualitative research method. A qualitative research method is related to developing explanations of social phenomena (Creswell, 2014). It is intended to help the researcher to gain the answers and understand the social phenomena. The research design in this study used a descriptive research case study following the current research focuses on understanding the perception from current issues faced by the student in the field. This study was conducted in one of universities in West Nusa Tenggara. This study involved 8 English students in semester 5 . These eight participants (4 male students and 4 female students) had online learning experiences for two semesters. Subsequently, the researcher sent consent letters to the participants and asked for permissions to get the data from the students. In response to this query, the students replied positively.

The data were collected from interview, observation, and documents. In interview section, the researcher used semistructure interview contained a mixture of closed-ended and open-ended questions. The researcher made list of interview questions related to students' perception of the use of online learning platform and students' attitudes toward online learning using online platforms as the guidelines. Each participant was interviewed for ten to fifty minutes. The data were recorded using Smartphone recording with the agreement from the participants. The observations were conducted twice in online learning process. The researcher observed students' attitudes during online learning process and the researcher took the notes in the observation sheets regarding students' activities or behavior in online meeting. The researcher also obtained the data from the students' documents. The document was done by analyzing students' documents contain students' tasks, and materials in asynchronous online learning platforms.

To strengthen the conformability of the data, the researcher applied triangulation. Triangulation is a validation approach based on the gathering of results achieved by using multiple investigators, data sources, methods, and theoretical perspectives (Johnson and Christensen, 2014). Thematic analysis was utilized to analyze data from interviews. The researcher observed the data carefully to look for the common themes that appear repeatedly from the data. The researcher grouped the data into several categories. Next, the data that did not include to any category were considered as individual peculiarity. Once the data was obtained, the researcher transcribed and interpreted them as basic for understanding the topic being investigated. In this research, the researcher started to analyze the data since the data collection was done. Data analysis

Based on Miles and Huberman (1994) is used in this research, which is involving three steps: data reduction, data display, and conclusion drawing/ verification.

\section{RESULT AND DISCUSSION}

The findings from interview, observation, and documents related to students' perception of the use of online learning platform for learning during the pandemic and students' attitudes toward using online learning platform consist of; first, findings related to students' perception contain several categories, i.e., (1) The disadvantages of the online learning platform for the students; (2) The advantages of the online learning platform for the students. However, based on the results, compared with the advantages, the disadvantages of using online learning platforms are more perceived by most students. The second, finding related to students' attitudes toward using online 
learning platforms contain three categories, i.e. (1) Students' learning behavior using the online learning platforms (2) Students' problems solving skill; (3) Online learning facilities.

As regards to students' perceptions, the first category of findings dealt with the disadvantages of online learning platforms that were used by the students for learning. The result of the interview indicated that some students complained that they faced many problems in using online learning platforms for learning during the pandemic. Students' problems emerged from both internal and external factors. In this relation, student 2 mentioned "the urgent problem is quota, especially in my home...very lack of internet connection". The same is true with the statement uttered by students 3 " $m m m$... there are so many... so many difficulties because of the distractions...internet connection...it always happened... and it made my online class room page suddenly come in and come out". Student 8 stated "sometimes the quota... the internet connection also sometimes comes and goes... and when my quota is running out, then, I skip the online class". The student also said, there are some online learning platforms that need a lot of quota. This is complained by student 2 "Yeah... Google Meet is kind of an expensive platform and I spend a lot of quota, and I also need to look for materials on other online platforms such YouTube, use this platform and I need a lot of quota". The students generally reported that they have problems with quota and internet connection. Consequently, the students undergo a difficulty in accepting and understanding the material which is delivered by the lecturer. For example, student 5 said "in online class for example, when I had trouble with internet connection I could not hear the explanation from my lecturer clearly". Similarly, student 4 uttered her frustration "It is really complicated when I have problem with internet connection, there is one of my lecturer do not believe it".
The second external factor deals with their environment. For example, student 5 mentioned "The atmosphere in my home is unconducive, and I think it does not support me to join online class, sometimes there is a noise from outside my home like the sound from chickens, and also from my neighbor... it is really noisy". On the other hand, student 7 stated "A trouble from my neighbor, the sound of their pets. Besides, the students also faced technical trouble in the online platform. Stated by student 6 "sometimes there is trouble in... in the Moodle. Usually, when a lot of students access that platform, the server goes down, and it takes time to collect the assignment".

Subsequently, some students reported internal factors as their problem. For example, student 7 "The problem is internally from myself, sometimes I feel so lazy, and sometimes I find it hard to understand the explanation from my lecturer". The same case came from students 4, she complained "Just lazy", I feel like I cannot learn under pressure all the time, I feel dizzy, as a result, I cannot understand the materials". Besides, student 2 had problems with comprehending the material. Student 2 said "I cannot understand the material easily, I need time to learn". Student 8 added "My consistency in learning sometimes has ups and downs". In addition, the use of the technology might affect students' health. As stated by student 3 "because... reading by the laptop or mobile phone made me feel...eye strain".

The result of the observations showed that some students have a problem with their internet connection as stated by student 3 in the interview section. Almost all students in class $X$ attended the meeting. However, some of them apparently left the class suddenly and joined the class again. The same problem as class $\mathrm{X}$ was also revealed in class $\mathrm{Y}$. Besides, in class $\mathrm{Y}$ also showed students' problems with the technology such as the microphone. Next, the data obtained from students' documents, most of the students assign their 
tasks in their online learning platform even though student 6 stated sometimes there is a problem in collecting the task on the online learning platform.

The implementation of distance learning using online platform during the pandemic is also brought some advantages. The data obtained from interview showed that some students enjoy the online learning process in pandemic era. Stated by student 7 "The thing make me enjoy...nobody is restraining me...I mean just feel free”. This online learning provides a flexible learning space for the students. Student 7 also said "mmm we can learn from home or campus or anywhere we want as long we have quota and internet connection". Student 5 added "we just learn at home, sometimes we don't need to open the camera, and we don't need wear formal suit, just sit in front of the laptop". The advantage of online learning platforms during pandemic is stated by student 1 "I can say... I can multitask", "when I was a chief of an English Festival event, I needed to go to some schools to share the invitation letter, but, at the same time I had a meeting class, fortunately, I can join the online meeting while sharing the invitation letter".

Every student has different learning behavior. From the interview section, the researcher revealed there are some students' learning behaviors. The students generally reported that they conduct an online discussion with their friends, as expressed by student 8 "usually we use WhatsApp, me and my friends usually use it to interact", "we interacted by chat if we have work in group, we usually talk by chat or video calls". Same behavior as student 8 , student 5 stated "We usually discuss in Whatsapps group, and also if we have work in group we use Google Meeting to discuss, maybe just for share the materials". Also student 2 said "Sometimes, I discuss with my friends, I send them personal message and ask them about the material". However, student 4 expressed different behavior, she stated "I learn by myself", "I seldom discuss with my friends". The other behaviour stated by student 8 "Sometimes, I feel lazy, really...and I always procrastinate to do my assignment, just waiting for the deadline".

Furthermore, students' learning behavior in synchronous online learning platforms is expressed by some students. For example, student 5 said "Sometimes some of my friends in the online class ask a question, or argue". Also stated by student 8 "when the lecturer gives us a question, we answer it or give some opinions". However, student 4 stated different things from students 5 and 8, she stated "I am lazy, sometimes I leave the online meeting sleep, and I seldom pay attention to it". Similarly expressed by student 1 "I turn off the camera, and I can lay down during the online meeting". In addition, student 3 said "A lot of students are too shy to ask questions and they turn off the camera".

The researcher was conducting the observation in class $\mathrm{X}$ and $\mathrm{Y}$. The data gained from observation showed the students on synchronous online meetings lacked interaction. In the online meeting, there were few students who responded to the lecturer, and in class X there were some students who did not respond when the lecturer gave them a question. Based on the observation in class $\mathrm{X}$ and $\mathrm{Y}$, the students generally turn off the camera as stated by students 1 and 3 in the interview section. Next, based on the students' document, most of the students have online group discussion. They discuss their material from the lecturer as stated by some students in the interview. The students also have an online group with their lecturer for the purpose of discussion and announce them the schedule. As stated by student 4 "by Whatsapps, Google Meet...the student made Whatsapps group discussion, and then invited the lecturer... the lecturer usually gives us an announcement in it".

From students' perception which is gained in the interview sections showed that a lot of the students have problems. However, every student has their own way to deal with their problem. The researcher 
recorded that the common problems which every student faced is an internet connection, and quota. For example, student 7 stated that sometimes he has a problem with his internet connection, and then he tried to solve the problem like he stated "sometimes I go to another place where I can get the WiFi". The same problem as student 7 , student 6 said "when my signal suddenly disappears, I usually reconnect it in my home, use my WiFi". On the other hand, some students stated that when they have a problem with the internet connection or quota, they skip the class. As expressed by student 4 "Nothing I can do, I just skip the class, and then, tell the lecturer that I have a problem", and student 8 mentioned "...and when my quota is running out, then, I skip the online class". These two students have their own way to solve that problem. Student 4 said "nah...if so... we get the pdf material in Spada...then I print it out, if I do not understand the material, I will try to ask my friends". The same way as student 4 , student 8 stated "when my internet connection is unstable, I just learn by myself and then I try to discuss it with my friends".

One of the students expressed that when they had a problem in their own environment they moved to another quiet place. As stated by student 1 "I usually move". The other way to solve this problem is stated by student 7 "I tell my parents not to call me during class... from this time until that time". The same problem as student 7 , student 2 also has the same way to solve this problem. As he tried "I usually briefing with my parents, tell them not to call me during the class".

The next finding dealt with the problem of comprehending the materials delivered by the lecturer. Some students generally coped with this problem by discussing it with their other friends. For example, student 2 stated "sometimes I discuss it with my friends". Student 5 also said "I usually ask my friends... ask them in online group discussion". The same way as two students above, student 8 stated "I ask my friends, actually I am shy if I try to ask a lecturer, so, I just try to ask my friends who know more about the materials". Besides, the other students tried to find another way such as they learn by looking for other references. As expressed by student 6 "If I do not understand the material, I try to look for it in the other references, in Google...". Also student 2 had the same way to solve this problem as student 6 did. Student 2 said "I try to find it out more by using the other platform".

Then, based on the interview results, some of the students perceived to have success in learning after trying to solve the problem in their own ways. For example, student 2 stated "Yeah, so far it works". Student 3 also said "It works, I am tethering to my sister". Same as student 2 and 3, student 5 had a problem with her internet connection during the meeting, then she tried to ask her friend and discuss what she missed in the online meeting, and student 5 perceived "It works...". However, student 8 had a different perception even after trying a way to solve her problem, student 8 said "It works, but not fully works".

The data obtained from the interview showed that the students used various online learning platforms for learning during pandemic. The students mention both synchronous and asynchronous online learning platforms that are used for learning. For synchronous online learning platforms, the students generally reported they used Google Meet to join face to face online meetings. For example, student 2 "During the pandemic, mostly we use Google Meet", and student 4 said "I use Google Meet". Besides, for other learning activities, student 3 mentioned the other online learning platforms the students used for learning during the pandemic, she stated "Zoom, Google Meet, and Google Classroom, and... Whatsapps, and Email sometimes when we want to collect an assignment".

Based on the observation, the researcher observed class $\mathrm{X}$ and $\mathrm{Y}$, which 
used Google Meet to create face to face online learning. Besides, some lecturers combined both synchronous and asynchronous online learning platforms to create online learning activity. For example, student 2 "The lecturer explains the material...the lecturer presents it in a screen meet, and also the lecturer provides us the material via Google Classroom, and Moodle... yeah ... it is clear enough". Next, based on students' documents, the students mostly collected their assignments via asynchronous online learning platforms, such as Google Classroom, Email, WhatsApp, and Spada. As stated by student 3 in the interview section.

The results of the present study indicated that every student faced the problem in using online learning platform during pandemic time. Students' problem came from both external and internal factors. However, the students have their own way to solve the problems. The results of this study also indicated that the use of online learning platforms during pandemic brought about advantages and disadvantages for the students. Some of the students expressed their negative perceptions toward online learning platforms. However, most students perceived that online learning platforms brought more advantages than disadvantages.

Related to the disadvantages of online learning, the result of the interview indicates that students complained that they faced many problems in using online learning platforms for learning during the pandemic. Students' problems emerged from both internal and external factors. In this relation, external factors contain; lack of internet connection, lack of quotas. It showed from observation results that almost all students in class $\mathrm{X}$ attended the meeting. However, some of them apparently left the class suddenly and joined the class again. The same problem as class $\mathrm{X}$ was also revealed in class $\mathrm{Y}$. Besides, in class $\mathrm{Y}$ also showed students' problems with the technology such as the microphone. Next, the data obtained from students' documents, most of the students assign their tasks in their online learning platform even though sometimes there is a problem in collecting the task on the online learning platform. Consequently, the students underwent a difficulty in accepting and understanding the material which is delivered by the lecturer. However, the only advantage that students' perceived was the flexibility of learning.

By using the theory of learning by Skinner (1953), behaviorism, the study found that stimulus had an important role in shaping students' responses to learning. The result of data analysis showed that when participants gained positive stimulus from their learning environment, they developed positive responses. Thus, they strengthened their own learning style. The result of the data analysis also showed that participants were able to explain their understanding of the subjects they learned in the online learning platform delivered by their lecturers.

The findings of the study suggest that online learning activities required collaboration in order that students could interact with the others. This supports the constructivism theory (Vygotsky, 1978) used for the study. The theory emphasized that students must be involved actively in the learning process to ensure learning engagement. The finding supports Harasim's (2012) theoretical stance, i.e. online collaborative learning Based on the result of the study, it is suggested that online collaborative learning needs to be enhanced in the future. Through this collaboration, participants could discuss their learning materials with their peers, and accomplished their tasks.

The study resumed that the cause of success and failures of students' results in learning appeared due to the components of attribution theory i.e., (1) Locus of control; (2) Stability; (3) Controllability.

The results of data analysis show that some of the participants blamed their environment for the discomfort as the cause 
of their income (external locus of control). In the same vein, another external factor found dealt with their environment. Besides, the students also faced technical trouble in using the online platform. The rest of participants blamed themselves as the cause of their success and failures in learning (internal locus of control), for example, some participants felt lazy to join the online meeting.

The causal factors of success or failure are attributed to stability of attitudes. In this theory, aptitudes and tasks difficulties are considered to be stable, while effort and luck are considered unstable. The result of data analysis showed that some of the participants put efforts in learning; however, some of them were unstable to maintain their effort in learning. Some of the participants expressed that sometimes felt that they were lacked ability to maintain their consistency in learning.

The last component of the cause of success and failures is related to controllability. The students' behavior which is the cause of their success or failures might be controllable or uncontrollable. When the individuals' behavior is controllable, then the individual has the ability to influence their results of learning, and when individuals' behavior is uncontrollable, the individuals' lack of ability to affect the results. The results of data analysis show that the participants were able to influence their learning results.

Some of the participants felt successfully understand the materials delivered by the lecturers in many ways. For example, when the participant had a problem with their learning environment, the participant tried to find a way to improve their learning space, and when the participant had difficulty to understand the materials, they tried to discuss with their peers. However, based on the principle of controllability, the impact of controllability of the behavior is based on the individual's locus of control and the stability of behavior. In conclusion, the results of the analysis show that participants generally have the ability to control their behavior, and they perceive to have success in accomplishing the learning materials and given tasks.

\section{CONCLUSION}

The only way to deliver material in the pandemic era is using online learning platforms. The use of online learning platform for learning during the pandemic may bring the advantage and the disadvantage for the students. However, the results of this study revealed that the disadvantage of online learning is more perceived than the advantage. Moreover, the students' attitudes in using online learning during the pandemic are also variety. Some of them felt lazy, and some of them felt uncomfortable in their own learning space. However, the students find their own way to solve the problem in learning.

Apart from the shortcomings contained in this study, the results of this study may provide benefits for the students to be aware of their learning styles. So, the students should do more of the things that are faced by the students when it comes to their learning environment, and try to more prevent it by doing more preparations. In addition, the results of this study can also provide informative input to lecturers to know students' problems or things they faced, so that lectures can prepare their teaching strategies to provide materials for students. The results of this study are also expected to deliver inspiration and innovative to other researchers to conduct study related to the students' perception and attitudes toward online learning during the pandemic.

\section{REFERENCES}

Al-Bataineh., Banikalef., Albashtawi. (2019). The Effect of Blended Learning on EFL Students Grammar Performance and Attitudes: An Investigation of Moodle. Arab World English Journal, 324-334. 
Albashtawi, A. B. (2020). The Effectiveness of Google Classroom Among EFL Students in Jordan: An Innovative Teaching and Learning Online Platform. Internationl Journal of Emerging Teachnology in Learning , 78-85.

Almpanis T., Miller E., Ross M., Price D., James R. (2011). Evaluating the Use of Web Conferencing Software to Enhance Flexible Curriculum Delivery. In C.A. Shoniregun \& G.A. Akmayeva (Eds), Proceeding of The Ireland International Conference on Education. (IICE2011) (pp.317-322). Dublim:IICE.

Bassey, M. (1999). Case Study Research in Educational Settings. Philadelphia USA: Open University Press

- Babayigit., Cizreliogullari., Altun. (2020). How Does Online Learning Facilitate Teaching? Is it a New Phenomenon or Due to Coronavirus? A Collection of Students' Views. International Online Conference on Economics and Social Sciences. 210-216

Chourishi. (2015). Effective E-Learning through Moodle. International Journal of Advance Technology \& Engineering Research , 34-37.

Clark, R. C., \& Mayer, R. E. (2016). Elearning and the science of instruction: Proven guidelines for consumers and designers of multimedia learning. John Wiley \& Sons.

Creswell, J.W. (2014). Research Design: Qualitative, Quantitative and Mixed Methods Approaches. Thousand Oaks, California: Sage Publications Ltd.

Garnham, C., \& Kaleta, R. (2002). Introduction to hybrid courses. Teaching with Technology Today, 8(6). Retrieved from http://www. wisconsin.edu/ttt/index.htm

Harasim, L. (2012). Learning theory and online technologies. Marceline,
MO: Walsworth Publishing Company

Harasim, L. (2012). Learning theory and online technologies. Marceline, MO: Walsworth Publishing Company

Heider F (1958) The psychology of interpersonal relations. Wiley, New York

Jan. (2020). A Phenomenological Study of Synchronous Teaching during COVID-19: A Case of An International School in Malaysia. Social Sciences \& Humanities Open 2 (2020) 1000842.

Johnson, R.B., \& Christensen, L. (2014). Educational Research: Qualitative, Quantitative and Mixed Methods Approaches $5^{\text {th }}$ Edition. USA: Sage Publications, Inc.

Marshall, Kostka. (2020). Fostering Teaching Presence through the Synchronous Online Flipped Learning Approach. The Electronic Journal for English as a Second Language, 1-8.

Miles, M. B., \& Huberman, A. M. (1994). An Expanded Sourcebook Qualitative Data Analysis ( $2^{\text {nd }}$ ed.). London: Sage Publication.

Novaie. (2020). Saudi University Students' Perceptions toward Virtual Education During Covid- 19

Pandemic: A Case Study of Language Learning Via Blackboard. Arab World English Journal , 5-13.

Skinner, Burrhus Frederic. Science and Human Behavior. New York, NY. (866 Third Ave., New York, NY 10022): The Free Press, 1953. Print.1

Patricia. (2020). College Students' Use and Acceptance of Emergency Online Learning Due to covid-19. International Journal of Educational Research Open, 3-20.

Weiner B, Heckhausen H, Cook R (1972) Causal ascriptions and achievement behavior: a conceptual analysis of 
LISDAYA: jurnal linguistik (terapan), sastra, dan budaya Vol. 17 Nomor 2 edisi Juli-Desember 2021 - P-ISSN: 1858-408X E-ISSN: 2722-5186

Hal. 47-56

URL. http://lisdaya.unram.ac.id/index.php/lisdaya

effort and reanalysis of locus of control. J Pers Soc Psychol 21(2):239-248 